\title{
Effects of Aldosterone and Potassium-Sparing Diuretics on Electrical Potential Differences across the Distal Nephron
}

\author{
JAMES B. Gross and JuHA P. KoKko \\ From the Department of Internal Medicine, The University of Texas Health Science Center, \\ Southwestern Medical School, Dallas, Texas 75235
}

\begin{abstract}
A B S TRACT We have previously shown that the transtubular potential of the rabbit cortical collecting tubule varies in concert with changes in plasma mineralocorticoid levels, while the potential of the distal convoluted tubule is invariant with such changes. In the present studies we have examined the effects of in vitro addition of $d$-aldosterone to isolated tubules, as well as the effects of triamterene and spirolactone.
\end{abstract}

$d$-Aldosterone $(0.2 \mu \mathrm{m}$ added to the perfusate or 1 $\mu \mathrm{M}$ added to the bathing medium) resulted in a marked stimulation of the transtubular potential difference (lumen-negative) after a short latent period. $d$-Aldosterone had no effect on the potential difference of distal convoluted tubules of intact or adrenalectomized rabbits. Both the magnitude of the response and the length of the latent period in the cortical collecting tubule after aldosterone were markedly temperature-dependent. Triamterene caused a gradual but reversible inhibition of the potential difference in the cortical collecting tubule but had no effect in the distal tubule. Spirolactone, when added before aldosterone, blocked the electrical response to the hormone in the cortical collecting tubule, and produced a gradual inhibition of the potential difference in mineralocorticoid-stimulated tubules. Spirolactone had no effect on the potential difference of the distal tubule.

We conclude that $(a)$ the influence of aldosterone on the potential across the distal nephron is restricted to the distal convoluted tubule, $(b)$ the electrical response to aldosterone and the latent period are temperature-dependent, $(c)$ the response to aldosterone is blocked by spirolactone, and $(d)$ triamterene

Received for publication 15 April 1976 and in revised form 10 September 1976. inhibits the potential difference only in the cortical collecting tubule.

\section{INTRODUCTION}

The intrarenal action of aldosterone has been a subject of considerable investigation in recent years. One aspect of this subject has been the site or sites within the distal nephron responsible for mineralocorticoidmediated changes in sodium and potassium excretion. Previous in vivo studies have suggested a site of action of aldosterone both in the distal convoluted tubule $(\mathrm{DCT})^{1}(1,2)$ and in the collecting duct $(3,4)$. However, our previous in vitro studies have indirectly suggested that only the cortical collecting tubule (CCT) and not the DCT is responsive to in vivo variations in mineralocorticoid secretion (5). Thus, the purpose of the present investigation is to directly examine this issue for the first time in isolated, perfused nephron segments, with specific reference to the site of action of aldosterone and the potassium-sparing diuretics, spirolactone and triamterene. The findings of this study provide direct support for our previous hypothesis that the lumen-negative potential difference (PD) in the CCT is mediated by aldosteronestimulated electrogenic sodium transport, while the lumen-negative potential in the DCT is insensitive to mineralocorticoid (5).

\section{METHODS}

Segments of CCT and DCT were perfused in vitro by the same technique described for other segments of the nephron (6). Female New Zealand rabbits weighing $1.5-2.5 \mathrm{~kg}$ were used in all experiments. Animals were given either standard

${ }^{1}$ Abbreviations used in this paper: CCT, cortical collecting tubule; DCT, distal convoluted tubule; DOCA, desoxycorticosterone acetate; $\mathrm{PD}$, potential difference. 
laboratory diet (containing $140 \mathrm{meq} / \mathrm{kg} \mathrm{Na}^{+}$and $390 \mathrm{meq} / \mathrm{kg}$ $\mathrm{K}^{+}$) with ad lib tap water or standard diet plus substitution of $0.9 \% \mathrm{NaCl}$ solution for tap water as a drinking source. A separate group of animals was fed the standard diet and also given desoxycorticosterone acetate (DOCA) $2 \mathrm{mg} / \mathrm{kg}$ per day, intramuscularly. These animals were sacrificed only after a minimum of 4 days on this regimen.

Several animals underwent bilateral total adrenalectomy before study. Animals were anesthetized with ketamine $\mathrm{HCl}$ and bilateral total adrenalectomy was carried out through a midline abdominal incision. Completeness of adrenalectomy was assessed by measurement of plasma corticosterone levels (7) $2 \mathrm{wk}$ or longer after adrenalectomy. Only those animals with undetectable plasma corticosterone values ${ }^{2}$ were used in subsequent experiments. Animals were maintained after adrenalectomy on a standard diet supplemented by salt tablets and $0.9 \% \mathrm{NaCl}$ solution as a drinking source, and given a replacement dose of dexamethasone i.m. $(0.05 \mathrm{mg} / \mathrm{kg}$ per day). Animals maintained on this regimen 3 wk or longer after adrenalectomy were used in subsequent experiments.

The kidney was quickly removed and cut into 1-2-mm slices. A segment of either CCT or DCT was dissected out in a chilled dish of artificial solution of the following composition: $\mathrm{NaCl}, 105 \mathrm{mM} ; \mathrm{KCl}, 5 \mathrm{mM} ; \mathrm{NaHCO}_{3}, 25 \mathrm{mM}$; $\mathrm{Na}_{2} \mathrm{HPO}_{4}, 4 \mathrm{mM}$; Na acetate, $10 \mathrm{mM} ; \mathrm{MgSO}_{4}, 1 \mathrm{mM} ; \mathrm{CaCl}_{2}$, $1.8 \mathrm{mM}$; glucose, $8.3 \mathrm{mM}$; alanine, $5 \mathrm{mM}$; total osmolality, $298 \mathrm{mosmol} / \mathrm{kg} \mathrm{H} \mathrm{H}_{2} \mathrm{O}$. In addition $5 \% \mathrm{vol} / \mathrm{vol}$ fetal calf serum was added to maintain tubular viability. The solution was kept at pH 7.4 by continuous bubbling with $95 \% \quad \mathrm{O}_{2}-5 \%$ $\mathrm{CO}_{2}$. CCTs, 0.5-2.0-mm in length, were dissected free and transferred to a Lucite perfusion chamber. The DCT was identified as previously described (5), and a $0.3-0.8-\mathrm{mm}$ segment was isolated and transferred to the perfusion chamber. All studies were carried out at $37^{\circ} \mathrm{C}$ except where otherwise noted. Tubules were perfused with the artificial solution listed above. The bath solution was identical except for the addition of $5 \% \mathrm{vol} / \mathrm{vol}$ fetal calf serum.

The transtubular electrical PD was measured by techniques previously reported (8). Equivalent bridges of 300 mosmol/liter Ringer's solution in $4 \%$ agarose were connected to the end of the perfusion pipette and to the bath. The other ends of the bridges were submerged in saturated $\mathrm{KCl}$ solution that contained Beckman (Beckman Instruments, Inc., Fullerton, Calif.) calomel half-cells. Both ends of the tubule were sealed from electrical and hydraulic leaks by first coating and then placing Sylgard 184 (Dow Corning Corp., Midland, Mich.) in the tips of the holding pipettes.

$0.2 \mu \mathrm{M} d$-aldosterone was added to the perfusate and 1.0 $\mu \mathrm{M}$ to the bath in those experiments where the effect of aldosterone on the transtubular PD was examined. Triamterene, $50 \mu \mathrm{M}$, was added to either bath or perfusate. Spirolactone, as either Aldactone A (SC-9420) or Aldadiene (SC-14266, Searle Laboratories, Chicago, Ill.) was added to the bath $(1.0 \mathrm{mM})$ in those experiments in which aldosterone-spirolactone interactions were examined. Since no difference was found between the effects of Aldadiene and Aldactone, the results of these experiments are reported in composite form. Stock solutions of $d$-aldosterone, triamterene, and spirolactones were made by adding the powdered reagent to absolute ethanol (owing to the extremely low water solubility of all of these agents) and diluted at the time of the experiment to the concentrations listed by addition of glass-distilled water. The final solutions were then added either to the perfusate or to the bath. Control solutions (containing the alcohol diluent) were made

${ }^{2}$ Corticosterone determinations were kindly performed by Dr. Celso Gomez-Sanchez.

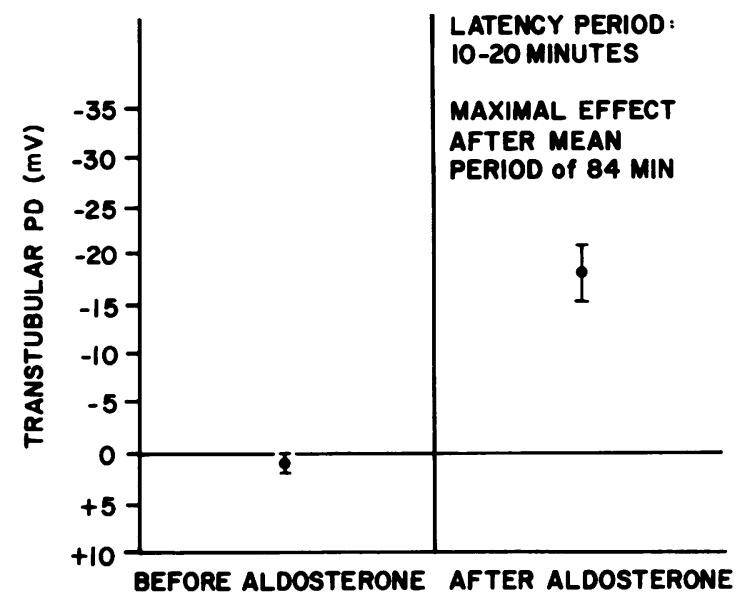

FIGURE 1 Effect of $d$-aldosterone (added to lumen) on the PD of the CCT. Addition of $d$-aldosterone $(0.2 \mu \mathrm{M})$ resulted in an increase in the magnitude of the transepithelial potential after an average latency of 10-20 min. Tubules were taken from high-salt animals and exhibited a low base-line potential. Studies were conducted at $37^{\circ} \mathrm{C}$.

up in the same manner but without the test agent, and were diluted and added to bath or perfusate in an identical way.

The results are expressed as mean $\pm \mathrm{SE}$ of number of tubules $(n)$ studied. The statistics were calculated by nonpaired $t$-test analysis.

\section{RESULTS}

Influence of aldosterone on the transtubular PD. As shown in Fig. 1, when CCTs were taken from animals on either a regular diet or one supplemented with $\mathrm{NaCl}$ and perfused at $37^{\circ} \mathrm{C}$, the potential difference was either a few millivolts positive or negative (with respect to the lumen), with an average value near zero, as we have shown previously (5). When $0.2 \mu \mathrm{M}$ $d$-aldosterone was added to the perfusate, a gradual and progressively electronegative potential developed (Fig. 1). This followed a latent period of $10-40 \mathrm{~min}$, the average latent time being $10-20 \mathrm{~min}$. The exact length of the latent period could not be determined because of the very gradual initial change in the slope of the transtubular PD, which thereafter increased progressively. After a mean of $84 \mathrm{~min}$, the potential had reached a value of $-19 \pm 3.1 \mathrm{mV}(n=6, P<0.001$ compared to control value). The results of several representative individual experiments are shown in Fig. 2. Addition of the diluent alone (control solutions) had no effect on the transepithelial potential.

When $0.2 \mu \mathrm{M} d$-aldosterone was added to the bathing solution, a consistent stimulatory response was not seen. However, when a concentration of $1.0 \mu \mathrm{M}$ was used, a similar pattern of progressive stimulation of the potential occurred. The latent period again averaged 10-20 min, and after a mean period of $116 \mathrm{~min}$, the 


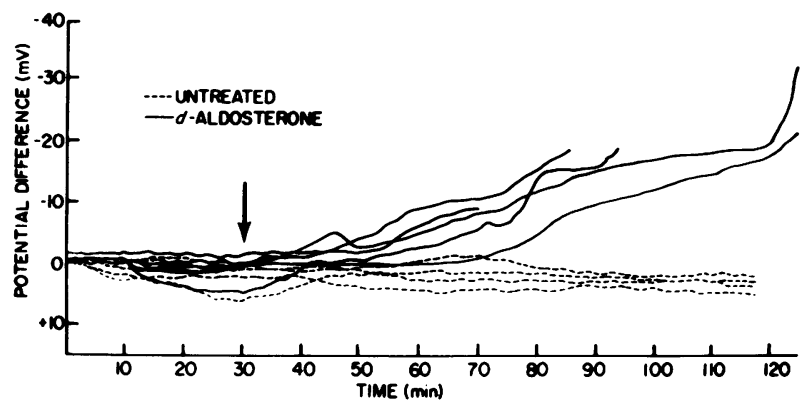

FIGURE 2 Representative experiments showing stimulation of the transepithelial potential of the CCT by $d$-aldosterone. After addition of $d$-aldosterone $(0.2 \mu \mathrm{M})$ to the perfusate (indicated by arrow), there was a progressive increase in the lumen-negative potential with time, after a short latent period (solid lines), in contrast with the maintenance of a value near zero in untreated control tubules (broken lines).

maximal PD response was $-18 \pm 4.5 \mathrm{mV}$, as shown in Fig. $3(n=5, P<0.001)$.

In contrast, when the DCT was perfused at $37^{\circ} \mathrm{C}$ and $d$-aldosterone was added to either the perfusing solution or to the bath, there was no discernible stimulation of the transtubular potential (Fig. 4). This was true both for tubules in which the base-line PD was relatively small as well as for tubules exhibiting a larger base-line value (Fig. 4). Furthermore, addition of $1.0 \mu \mathrm{M} d$-aldosterone to the bath solution of DCT segments taken from totally adrenalectomized animals (Fig. 4, broken lines) also had no apparent influence on the transtubular PD.

Effect of bilateral total adrenalectomy on the transtubular PD. The issue of aldosterone dependency of the PD was examined further by measuring the PD in both the CCT and DCT from rabbits having previously undergone bilateral total adrenalectomy. Animals were sacrificed $3 \mathrm{wk}$ or longer after adrenalectomy and tubules were studied only from those

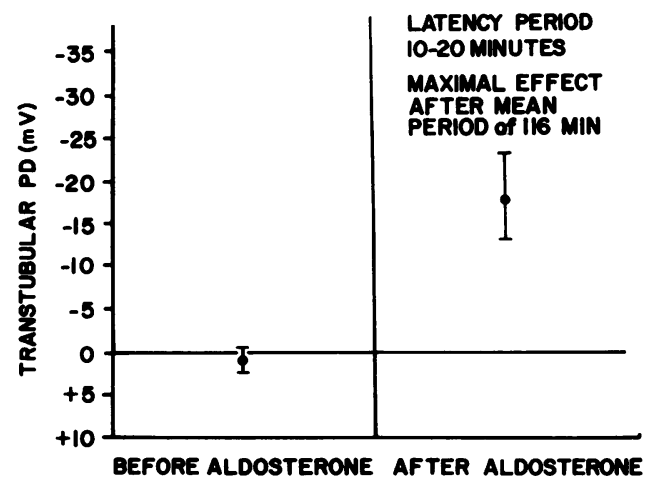

Figure 3 Effect of $d$-aldosterone $(0.2 \mu \mathrm{M}$ added to bath) on the transepithelial potential of the CCT. The response was similar to that shown in Fig. 2. animals with undetectable plasma corticosterone values.

The PD measured in all CCTs from adrenalectomized animals was consistently a small positive value, averaging $+1.6 \pm 0.7 \mathrm{mV}(n=6)$ (Fig. 5). This value was markedly discrepant from the mean $P D$ of $-33.6 \pm 5.1 \mathrm{mV}(n=9)$ observed in intact animals given DOCA $(P<0.001)$ (Fig. 5$)$.

The PD in the DCT of adrenalectomized animals, however, was no different from that in intact animals given DOCA (Fig. 5), the average value in adrenalectomized animals being $-30 \pm 8.0 \mathrm{mV}(n$ $=5)$ and that in intact animals $-34 \pm 5.5 \mathrm{mV}(n=5)$. These values were not statistically different $(P>0.10)$.

Temperature dependency of aldosterone response in the CCT. In the present studies a short latent period of 10-20 min for onset of aldosterone effect was observed, whereas the aldosterone-mediated increase in short-circuit current across the toad bladder begins after a latent period of 40-90 min (9-11). Because the present studies were carried out at $37^{\circ} \mathrm{C}$, whereas the toad bladder experiments were done at room temperature $\left(22^{\circ}-24^{\circ} \mathrm{C}\right)$, we examined the influence of alterations in ambient temperature on the aldosteronemediated increase in PD in the CCT. These data are depicted in Fig. 6. When tubules were perfused at $27^{\circ} \mathrm{C}$, addition of $d$-aldosterone to bath or to perfusate resulted in no discernible response of the transtubular PD, even when tubules were perfused as long as $120 \mathrm{~min}$ after addition of the hormone. When the temperature of the bath was subsequently raised to $37^{\circ} \mathrm{C}$, in the continued presence of aldosterone, there was, however, a definite and progressive stimulation

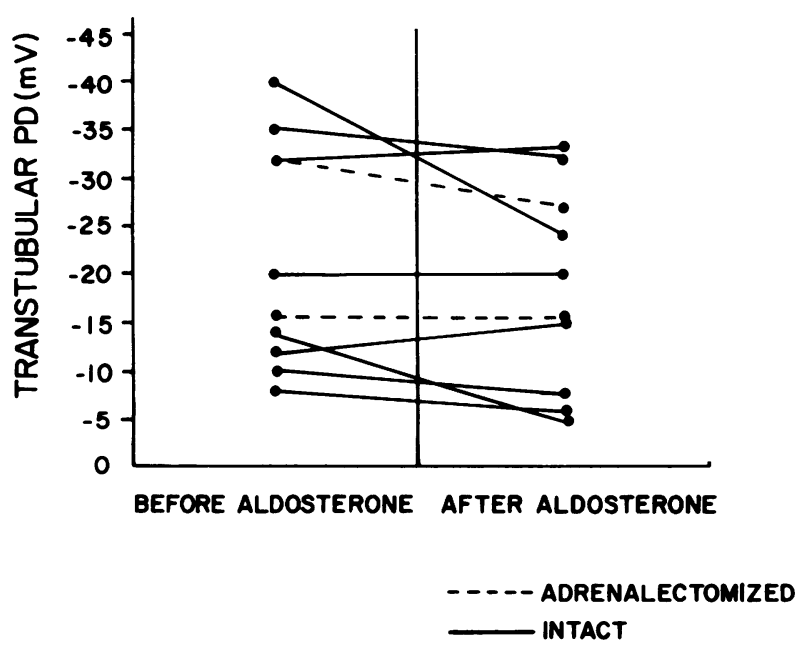

FIGURE 4 Lack of effect of $d$-aldosterone on the transepithelial potential of the DCT. There was no discernible response of the potential to addition of either $0.2 \mu \mathrm{M}$ to the lumen or $1.0 \mu \mathrm{M} d$-aldosterone to the bath in both intact and totally adrenalectomized animals. 


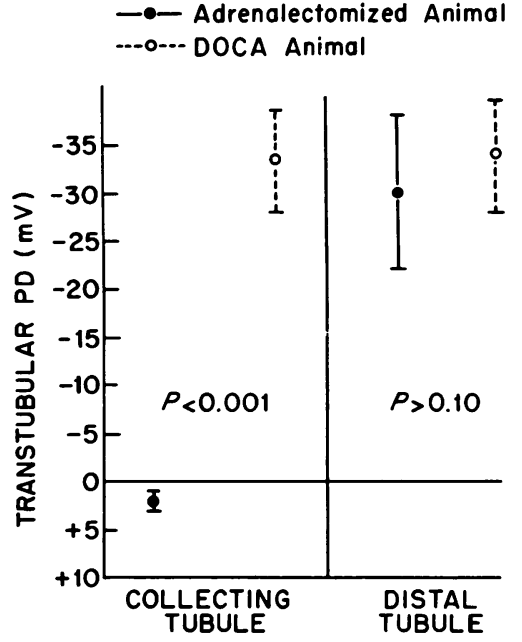

FIGURE 5 Effect of adrenalectomy on the spontaneous potential of the CCT and DCT. The PD was a small positive value in collecting tubules taken from adrenalectomized animals, strikingly different from the value obtained in intact animals given DOCA. In the distal tubule, the values for the potential in tubules from adrenalectomized and intact DOCA-treated animals were not significantly different.

of a lumen-negative potential. When tubules were perfused at $32^{\circ} \mathrm{C}$, addition of $1.0 \mu \mathrm{M} d$-aldosterone to the bath resulted in a very small stimulation of the transtubular PD after a mean latent period of $49 \mathrm{~min}$ (range 15-75 min). A subsequent increase in the bath temperature to $37^{\circ} \mathrm{C}$, in the continued presence of aldosterone, caused a further increase in the negative PD. Thus, both the magnitude of the response to aldosterone and the latent period were influenced by alterations in ambient temperature $\left(32^{\circ} \mathrm{C}\right.$ vs. $\left.37^{\circ} \mathrm{C}\right)$, and at $27^{\circ} \mathrm{C}$ no discernible aldosterone response could be detected. Tracings from representative experiments done at $27^{\circ} \mathrm{C}$ and $32^{\circ} \mathrm{C}$ are shown in Fig. 7 .

CCTs were also perfused at $27^{\circ} \mathrm{C}$ or $32^{\circ} \mathrm{C}$ in the absence of $d$-aldosterone, and the temperature was subsequently increased to $37^{\circ} \mathrm{C}$ at varying time intervals after initiation of perfusion (up to $90 \mathrm{~min}$ ). In the absence of $d$-aldosterone, increasing the ambient temperature to $37^{\circ} \mathrm{C}$ did not result in progressive stimulation of the lumen-negative potential. In fact, the potential either was unchanged or actually became more positive (Fig. 8).

Effect of triamterene. To examine the influence of triamterene on the PD in the CCT, tubules were taken from animals given $2 \mathrm{mg} \mathrm{DOCA} / \mathrm{kg}$ per day. The base-line potential under these circumstances was $-26.3 \pm 4.3 \mathrm{mV}$. Addition of $50 \mu \mathrm{M}$ triamterene to the bathing solution produced a gradual and progressive inhibition of the potential after a latent period of approximately $10 \mathrm{~min}$, the final PD being zero ( $n=6$, Fig. 8); this inhibition was reversible on wash-

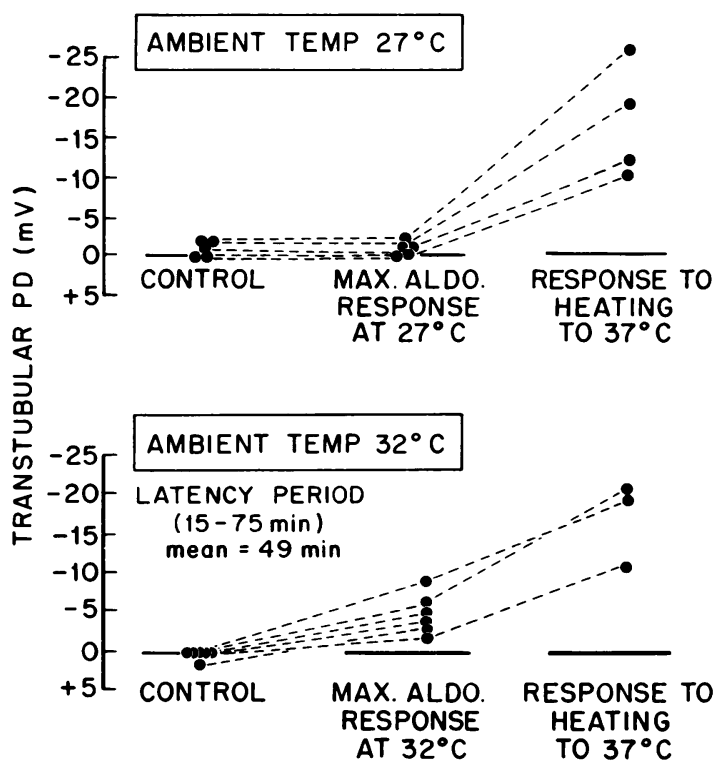

FigURE 6 Effect of ambient temperature on the response of the transepithelial potential to $d$-aldosterone in the CCT. Addition of $d$-aldosterone $(1.0 \mu \mathrm{M})$ to tubules perfused at $27^{\circ} \mathrm{C}$ had no discernible effect on the PD for as long as $150 \mathrm{~min}$ after initiation of perfusion (see text). Heating to $37^{\circ} \mathrm{C}$ in the continued presence of the hormone resulted in a prompt and progressive increase in the potential. At $32^{\circ} \mathrm{C}$ the latent period averaged $49 \mathrm{~min}$, and the maximal response was small compared to that at $37^{\circ} \mathrm{C}$ (see Fig. 2). Subsequent heating to $37^{\circ} \mathrm{C}$ resulted in a further increase in the potential.

ing triamterene from the bathing solution. The same concentration of triamterene $(50 \mu \mathrm{M})$ had no influence on the potential when added to the perfusate.

Also depicted in Fig. 9 are the results of addition

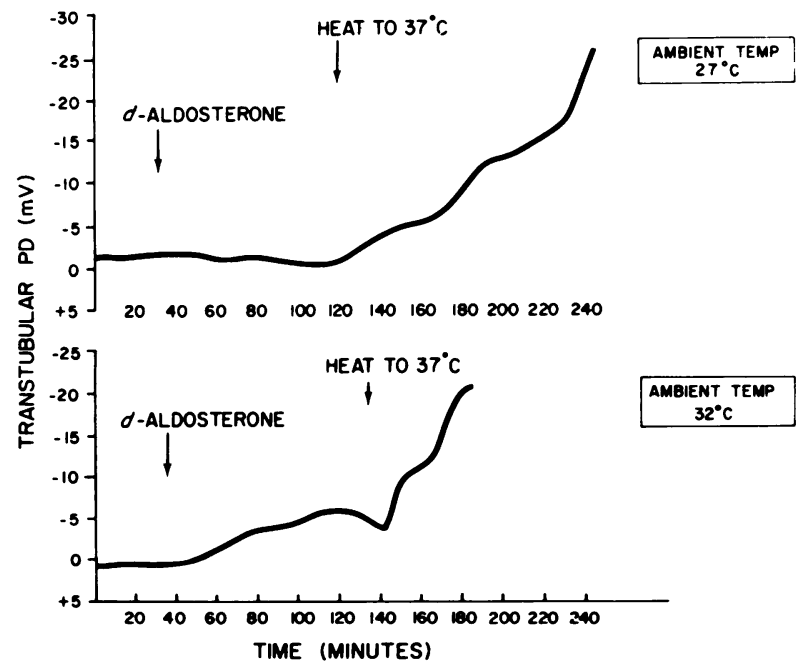

FIGURE 7 Representative tracings of experiments showing temperature dependence of aldosterone response. Protocol for the experiments is described in Fig. 6 and text. 


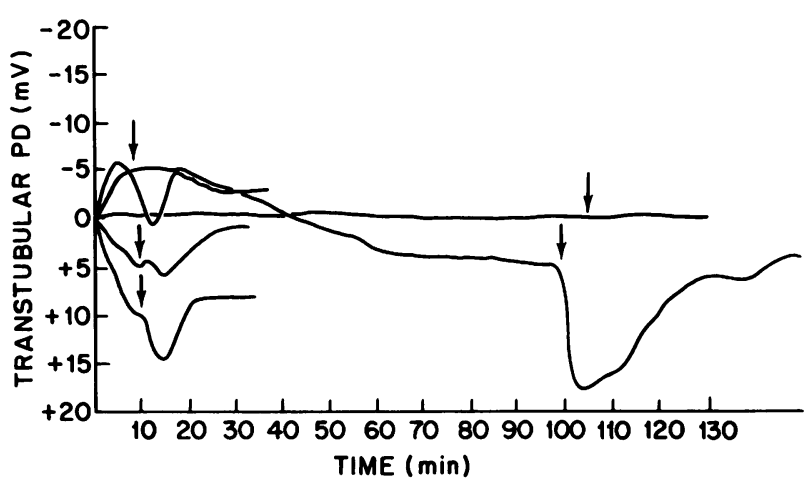

FIGURE 8 Effect of ambient temperature on the transepithelial potential of the CCT in the absence of aldosterone. Tubules were taken from animals with suppressed aldosterone secretion (high-salt diet, see text). The baseline potential was near zero, either a small positive or small negative value. When the ambient temperature was raised from $27^{\circ} \mathrm{C}$ to $37^{\circ} \mathrm{C}$ (indicated by the arrows), there was either no change in the potential or an increase toward a more positive value.

of $50 \mu \mathrm{M}$ triamterene, to either the bath or perfusate of the DCT. As shown, there was no discernible influence of this agent on the PD in this segment.

Effect of spirolactones. The interaction of mineralocorticoids and spirolactone was examined by adding spirolactone, either as Aldactone or Aldadiene, to the bathing solution of tubules from animals given i.m. DOCA. In these studies we measured the effect of spirolactone on the negative transtubular PD. A dose of $1.0 \mathrm{mM}$ spirolactone was chosen, a large molar excess, since it has previously been shown that effective competitive displacement of aldosterone by spirolactone requires at least a 1:100 molar ratio, $(12,13)$, although the absolute ratio varies with the affinity of the spirolactone studied (12). In the present studies a dose of $1.0 \mu \mathrm{M}$ aldosterone was used in stimulating the PD. In a second group of experiments, tubules were taken from animals given a high-salt diet, which therefore exhibited a base-line PD near zero. $1.0 \mathrm{mM}$ spirolactone was first added to the bathing solution, and after $10 \mathrm{~min} 1.0 \mu \mathrm{M}$ aldosterone was also added to the bath. In both sets of experiments, because of the limited water solubility of either spirolactone at this dosage, addition to the aqueous bath solution resulted in some precipitation of the agent; thus, the exact final concentration in solution was probably somewhat less than $1.0 \mathrm{mM}$.

Table I depicts the results of addition of $1.0 \mathrm{mM}$ spirolactone to the bathing solution of the CCT from DOCA-treated rabbits. After an approximately 10-15min latent period, there was a gradual inhibition of the negative potential, which decreased from a mean value of $-26.4 \pm 10.0$ to $-4.6 \pm 0.8 \mathrm{mV}(n=5, P$ $<0.005)$. This inhibition was not reversible on wash- ing the drug (as well as, presumably, the displaced mineralocorticoid) from the bath.

When tubules with a low base-line PD were pretreated with spirolactone, subsequent addition of $10 \mu \mathrm{M} d$-aldosterone to bath failed to cause a progressive increase in the magnitude of the negative PD, even when tubules were observed for as long as $90 \mathrm{~min}$ after addition of aldosterone. Fig. 10 depicts the results of a representative experiment.

Addition of $1.0 \mathrm{mM}$ spirolactone to the DCT had no discernible influence on the negative PD exhibited by this segment.

\section{DISCUSSION}

The current studies are the first to examine directly the specific site in the distal nephron where aldosterone effects are expressed. These studies clearly demonstrate that aldosterone produces a marked stimulation of the base-line potential across segments of CCT. In contrast, the DCT, which exhibits a marked lumen-negative $\mathrm{PD}$, shows no response of the potential to addition of $d$-aldosterone to either the luminal or bathing solutions. We have previously shown that both the CCT and the DCT exhibit active electrogenic transepithelial sodium transport and that this process is largely if not exclusively responsible for the negative PD observed in these two segments (5).

The present findings of a stimulatory effect of aldosterone on the negative PD in the collecting duct are in qualitative agreement with previously published studies on the effect of aldosterone on the PD and short-circuit current in the toad bladder (9-11). In agreement with the current studies, Porter and Edel-

$C=$ CONTROL $E=$ TRIAMTERENE $R=R E C O V E R Y$
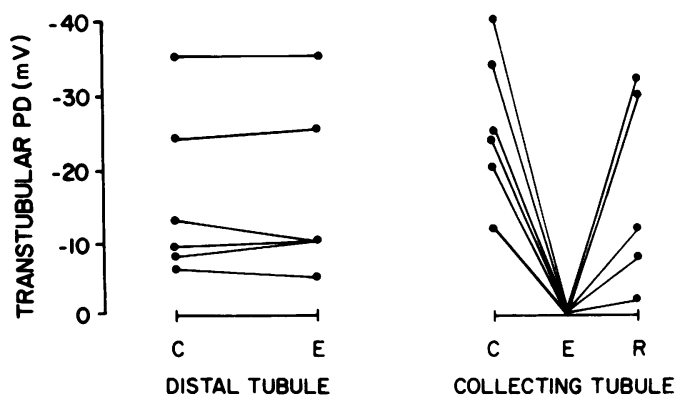

FIGURE 9 Effect of triamterene on the transepithelial potential of the CCT and DCT. In the distal tubule, addition of triamterene $(50 \mu \mathrm{M})$ had no effect on the PD. Addition of triamterene to the bath of the CCT resulted in a gradual but reversible inhibition of the potential. CCTs were taken from DOCA-treated animals and exhibited markedly negative base-line potential values. 
man (11) found that aldosterone $(0.1 \mu \mathrm{M})$ was effective in stimulating both the PD and short-circuit current of the toad bladder when added either to the mucosal or to the serosal surface. The only significant difference between previously reported toad bladder observations and our findings is the much shorter latent period in the current studies. Our additional findings of a marked influence of ambient temperature on both the latent period and the magnitude of the voltage response to the hormone offers a reasonable explanation for this discrepancy, however. The data indicate that as ambient temperature is reduced, the latent period lengthens and the magnitude of the potential rise in response to aldosterone is reduced. Similar conclusions were reached by Porter in studies on the influence of temperature on aldosterone-stimulated sodium transport in the toad bladder (14). Dalton and Snart also found that reduction of temperature diminished the magnitude of stimulation of the shortcircuit current by aldosterone (15). Thus the longer latent period of $40-90 \mathrm{~min}$, reported for the toad bladder studies done at $22^{\circ}-24^{\circ} \mathrm{C}$ compared with the current finding of a $10-20 \mathrm{~min}$ latent period of $37^{\circ} \mathrm{C}$, is consistent with the temperature dependency observations. In addition, there may be intrinsic species differences in the time constants of tissue response to aldosterone between the anuran toad and mammalian rabbit.

In the absence of direct measurements of transepithelial fluxes, the observed influence of aldosterone on the PD in the CCT provides only inferential evidence for enhancement of of net sodium transport. The underlying assumption is that stimulation of the $P D$ reflects an increase in net sodium transport. There is, however, no reason to doubt such an assumption.

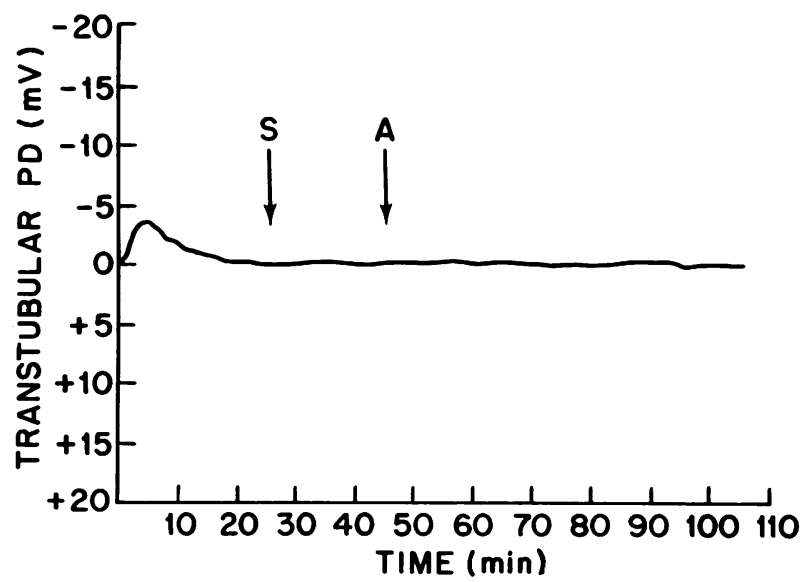

FIGURE 10 Effect of pretreatment of CCTs with spirolactone on the subsequent response to $d$-aldosterone. Addition of $1.0 \mathrm{mM}$ spirolactone to the bath 10-20 min before addition of $1.0 \mu \mathrm{M} d$-aldosterone completely blocked the response of the potential to the hormone.
TABLE I

Effect of Spirolactone on the Transepithelial Potential of the CCT

\begin{tabular}{ccc}
\hline Tubule & Control PD & $\begin{array}{c}\text { PD after } 1.0 \mathrm{mM} \\
\text { spirolactone* }\end{array}$ \\
\hline & $m V$ & $m V$ \\
1 & -64 & -5 \\
2 & -30 & -7 \\
3 & -15 & -2 \\
4 & -12 & -4 \\
5 & -11 & -5 \\
Mean SEM & -26.4 & $-4.6 \ddagger$ \\
SEM & 10.0 & 0.8 \\
\hline
\end{tabular}

* Added to the bathing solution as either Aldactone or Aldadiene.

$\ddagger P<0.05$ compared to control.

In the toad urinary bladder, there is a very close correlation between stimulation by aldosterone of net sodium transport, the short-circuit, and the transepithelial PD (11). It is nevertheless conceivable that the absence of a change in potential in the DCT after aldosterone might not indicate a lack of effect on sodium transport. If this were so, however, it would require that stimulation of lumen-to-bath sodium efflux be either electrically neutral or accompanied by an equal and opposite change in transtubular electrical resistance.

It might also be argued that failure to observe a stimulation of the potential by aldosterone in the DCT might be due to the high base-line PD observed, reflecting pre-existent near-maximal transport. However, even in tubules with base-line PD's in lower range (Fig. 4), aldosterone failed to have any influence on the potential. Also against this possibility is the finding of essentially the same PD in tubules dissected from totally adrenalectomized animals as in those given a maximal dose of mineralocorticoid (Fig. 5). The evidence therefore strongly indicates a lack of effect of mineralocorticoids in the DCT of the rabbit. These findings agree with our previous observations (5). Caution should be exercised, however, is extrapolating these findings to other species, since there may be species variations in the anatomical distribution of mineralocorticoid receptors.

Although the previous studies of Hierholzer et al. (2) reported an apparent influence of aldosterone on sodium reabsorption in the DCT of the rat, these studies cannot be clearly interpreted because of the recent demonstration of heterogeneity of the epithelium of surface tubules termed by micropuncture techniques as DCT (16). The study of Woodhall and Tisher also indicated that $50 \%$ of surface "distal" tubules of the Wistar rat were CCTs. Thus the findings by Hierholzer 
et al. (2) of a reduction in sodium transport in adrenalectomized Wistar rats are difficult to interpret in terms of localization of aldosterone action to a specific epithelial type. Uhlich et al. have reported a stimulatory effect of aldosterone on sodium transport in the collecting duct of the rat, but other distal nephron sites were not examined (4). Moreover, in the last-named study the increase in net sodium flux out of the collecting duct was entirely attributable to a decrease in the back-flux of sodium. An increase in unidirectional lumen-to-blood sodium flux was not demonstrable, a finding in conflict with all previous evidence regarding stimulation of sodium transport. Studies performed in such tissues as toad bladder (10, 11), which has striking transport similarities to mammalian collecting duct, have shown that stimulation of mucosa-to-serosa sodium flux quantitatively accounts for the increase in net sodium transport observed.

It is of interest that triamterene inhibited the PD in the CCT and was without effect in the DCT. These findings in the CCT agree with observations made by Gatzy in the toad bladder, where triamterene inhibited the PD and short-circuit current when added to the serosal border (17). Gatzy also found a slow time-course of action of triamterene (17). At a dose of $10 \mu \mathrm{M}$, the effect was reversible, whereas at higher doses the response was irreversible. Although an inhibitory response could be observed when triamterene was added to the mucosal medium, at least 10 times the dose was required to elicit a response comparable to that seen with serosal addition of the drug (17).

Also of note in the current studies is the observation that triamterene is effective at a site in the distal nephron that is also the target tissue for aldosterone action. In clearance studies, triamterene causes a sodium diuresis and reduction in urinary potassium excretion even in adrenalectomized animals (18) and man (19). In view of the current studies it is not completely clear why triamterene would still be effective in adrenalectomized animals. One possibility deserves consideration, however. In the toad bladder, even in the absence of aldosterone, there is a basal rate of sodium transport which is subsequently stimulated by addition of the hormone (11). It is possible that a similar aldosterone-independent basal rate of sodium transport exists in the rabbit collecting duct. Triamterene, which Eigler and Crabbe found to have similar pharmacologic action to amiloride (20), an agent that completely blocks sodium transport, may inhibit both basal and aldosterone-stimulated sodium transport. In this regard it is of interest that the maximal degree of inhibition of the negative potential in the current studies was not as great with spirolactone as with triamterene (Table I and Fig. 8).
Spirolactone, when added to the bathing solution of the CCT before addition of aldosterone, completely blocked the response to the hormone, a finding in complete agreement with previous observations on the interaction between these agents in other experimental systems $(13,17,21)$. This finding also confirms the specificity of the progressive rise in the magnitude of negative PD observed in the current studies after addition of aldosterone to bathing or perfusing solutions. In keeping with the expected action of a competitive inhibitor, spirolactone in a very large dose of $1.0 \mathrm{mM}$ caused a progressive fall in the potential when added to the bath of tubules taken from DOCAtreated animals (Table I). This finding is also in agreement with similar experiments done in the toad bladder (13). In the present studies, when the drug was washed from the bath, there was no subsequent recovery of the potential, a finding which is consistent with displacement of tissue-bound mineralocorticoid by the drug, with subsequent washing of both drug and displaced hormone from the system by repeated bath exchanges.

In summary, the present studies have demonstrated a direct stimulation of the negative PD in the CCT by $d$-aldosterone, as well as dependency of the negative potential on mineralocorticoid action. In contrast, the negative PD exhibited by the DCT is independent of mineralocorticoid and shows no response to addition of $d$-aldosterone. The stimulation of the potential in the collecting tubule can be blocked by spirolactones. Triamterene inhibits the PD in the CCT but has no effect on the potential of the DCT. Finally, the time-course and magnitude of the voltage response to aldosterone in the collecting tubule are markedly temperature-dependent.

These findings further extend the sharp functional segmentation of the distal nephron, which we have previously demonstrated (5), and underscore the need for careful anatomic localization in future physiologic studies of the morphologically and functionally heterogeneous distal nephron.

\section{ACKNOWLEDGMENTS}

We wish to acknowledge Dr. Celso Gomez-Sanchez for performing the plasma corticosterone determinations for us.

This work was supported in part by U.S. Public Health Service Program Project grant POl HL 11662, National Institute of Arthritis and Metabolic Diseases Research grant 1 RO1 AM 14677, and National Institute of General Medical Sciences Research Fellowship grant 1 T22 GM 00034.

\section{REFERENCES}

1. Hierholzer, K., M. Wiederholt, H. Holzgreve, G. Giebisch, R. M. Klose, and E. E. Windhager. 1965. Micropuncture study of renal transtubular concentration gradients of sodium and potassium in adrenalec- 
tomized rats. Pflügers Archiv Gesamte Physiol. Menschen Tiere. 285: 193-210.

2. Hierholzer, K., M. Wiederholt, and H. Stolte. 1966. Hemmung der Natriumresorption in proximalen und distalen Konvolut adrenalektomierter Ratten. Pflügers Archiv Gesamte Physiol. Menschen Tiere. 291: 43-62.

3. Uhlich, E., C. A. Baldamus, and K. J. Ullrich. 1969. Einfluss von Aldosteron auf der Natriumtransport in den Sammelrohren der Säugetierniere. Pflügers Arch Eur. J. Physiol. 308: 111-126.

4. Uhlich, E., R. Halbach, and K. J. Ullrich. 1970. Einfluss von Aldosteron auf den Ausstrom markierten Natriums aus den Sammelrohren der Ratte. Pflügers Arch. Eur. J. Physiol. 320: 261-264.

5. Gross, J. B., M. Imai, and J. P. Kokko. 1975. A functional comparison of the cortical collecting tubule and the distal convoluted tubule. J. Clin. Invest. 55: 12841294.

6. Kokko, J. P. 1970. Sodium chloride and water transport in the descending limb of Henle. J. Clin. Invest. 49: $1838-1846$.

7. Gomez-Sanchez, C., B. A. Murray, D. C. Kem, and N. M. Kaplan. 1975. A direct radioimmunoassay of corticosterone in rat serum. Endocrinology. 96: 796-798.

8. Kokko, J. P. 1973. Proximal tubule potential difference. Dependence on glucose, $\mathrm{HCO}_{3}$, and amino acids. $J$. Clin. Invest. 52: 1362-1367.

9. Sharp, G. W. G., and A. Leaf. 1964. Biological action of aldosterone in vitro. Nature (Lond). 202: 1185-1188.

10. Crabbe, J. 1961. Stimulation of active sodium transport by the isolated toad bladder with aldosterone in vitro. J. Clin. Invest. 40: 2103-2110.

11. Porter, G. A., and I. S. Edelman. 1964. The action of aldosterone and related corticosteroids on sodium transport across the toad bladder. J. Clin. Invest. 43: 611620 .
12. Funder, J. W., D. Feldman, E. Highland, and I. S. Edelman. 1974. Molecular modifications of anti-aldosterone compounds: effects on affinity of spirolactones for renal aldosterone receptors. Biochem. Pharmacol. 23: 14931501 .

13. Porter, G. A., and J. Kimsey. 1972. The effect of a new antialdosterone agent SC-19886 on aldosterone-stimulated transepithelial sodium transport.J. Steroid Biochem. 3: 201-208.

14. Porter, G. A. 1975. Action of aldosterone on transepithelial sodium transport. In Basic Life Sciences Vol. 6: Enzyme Induction. Dennis V. Parke, editor. Plenum Publishing Corporation, New York. 105-141.

15. Dalton, T., and R. S. Snart. 1967. Effect of hormones on the permeability of toad bladder (Bufo marinus). Biochim. Biophys. Acta. 135: 1059-1062.

16. Woodhall, P. B., and C. C. Tisher. 1973. Response of the distal tubule and cortical collecting duct to vasopressin in the rat. J. Clin. Invest. 52: 3095-3108.

17. Gatzy, J. T. 1971. The effect of $\mathrm{K}^{+}$-sparing diuretics on ion transport across the excised toad bladder. $J$. Pharmacol. Exp. Ther. 176: 580-594.

18. Baba, W. I., G. R. Tudhope, and G. M. Wilson. 1962. Triamterene, a new diuretic drug. I. Studies in normal men and in adrenalectomized rats. II. Clinical trial in oedematous patients. Br. Med. J. 2: 756-764.

19. Liddle, G. W. 1961. Specific and non-specific inhibition of mineralocorticoid activity. Metab. Clin. Exp. 10: 1021-1030.

20. Eigler, J., and J. Crabbe. 1969. Effect of diuretics on active Na-transport in amphibian membranes. In Renal Transport and Diuretics. K. Thurau and H. Jahrmärker, editors. Springer-Verlag KG, Berlin, W. Germany. 195-208.

21. Porter, G. A. 1968. In vitro inhibition of aldosteronestimulated sodium transport by steroidal spirolactones. Mol. Pharmacol. 4: 224-237. 